\title{
Descrição da Primeira Fase do Workflow CellHeap para Análise Single-Cell RNA-seq
}

\author{
Gabriel P. T. Silva ${ }^{1}$, Maria Clicia S. de Castro ${ }^{1}$, Vanessa S. Silva ${ }^{2}$, Fabricio A. B. \\ Silva ${ }^{2}$
}

${ }^{1}$ Instituto de Matemática e Estatística - Universidade do Estado do Rio de Janeiro

(UERJ) Rio de Janeiro - RJ - Brazil

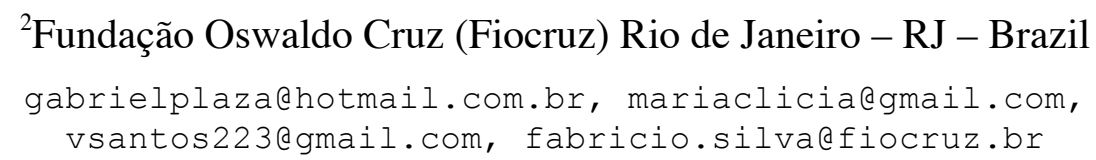

\begin{abstract}
This paper describes the initial step of the CellHeap workflow used in the data analysis of the single-cell sequencing (scRNA-seq). Phase 1 of this workflow consists of the download and validation of the accession data to be used in subsequent phases. Finally, some planned improvements to this step are described.
\end{abstract}

Resumo. Este artigo descreve a etapa inicial do workflow CellHeap utilizado na análise dos dados de sequenciamento de células únicas (scRNA-seq). A Fase 1 consiste no download e validação dos dados de amostras a serem utilizadas nas fases subsequentes. Ao fim, são descritas algumas melhorias planejadas para esta etapa.

\section{Introdução}

Atualmente, diversas centenas de terabytes de dados de sequenciamento de células únicas (scRNA-seq) estão disponíveis em repositórios públicos. Estes dados são relacionados a tecidos, comorbidades e condições.

Os protocolos de sequenciamento de células únicas (scRNA-seq) desenvolvidos nos últimos anos permitem um melhor conhecimento dos sistemas biológicos. Eles podem requerer infraestrutura de software e de sistemas computacionais de larga escala, dependendo da quantidade de dados utilizada.

O workflow CellHeap (Silva et al, 2021) foi concebido para realizar análises single-cell RNA-seq (scRNA-seq) voltadas ao estudo da COVID-19. A relevância deste tipo de análise reside na compreensão mais precisa do transcriptoma em células individuais. As tecnologias scRNA-seq geram conjuntos de dados que descrevem o estado de células individuais com resolução sem precedentes (Nicolás e Costa, 2021).

Neste contexto, temos um grande volume de dados por amostra que deve ser armazenado e tratado, o que acarreta desafios de natureza computacional a medida que a disponibilidade de dados públicos continua aumentando e os estudos passam a lidar rotineiramente com conjuntos de dados cada vez maiores. Portanto, é necessária uma infraestrutura computacional poderosa. 
O workflow CellHeap foi projetado e desenvolvido para execução no supercomputador Santos Dumont, um dos mais importantes da América Latina, situado no Laboratório Nacional de Computação Científica (LNCC).

Na Seção 2 apresentamos o workflow CellHeap e na Seção 3 concluímos apresentando os próximos passos de implementação do workflow.

\section{Fases do Workflow}

O workflow CellHeap é dividido em 5 fases como mostra a Figura 1. Ele segue um esquema de pipeline onde as saídas de uma fase são as entradas das fases subsequentes e podem ser usadas diferentes ferramentas em cada fase. Cada uma das fases está descrita a seguir.

A Fase 1 é responsável pela curadoria, download e validação dos dados brutos. A Fase 2 gera informações sobre os dados da amostra, que podem ou não ser agregados. Por exemplo, um dos arquivos de saída da Fase 2 é uma matriz de contagem de genes. A Fase 3 é responsável pelo controle de qualidade na geração das células de interesse. É nesta fase que devem ser removidos da amostra artefatos como códigos com células duplicadas. A Fase 4 reduz a dimensionalidade e forma cluster com os genes selecionados. A Fase 5 contém uma grande quantidade de análises diferentes em nível celular ou genético.

Observamos que as Fases 1 e 2 são as que consomem maior quantidade de tempo de execução e armazenamento de memória se comparados às Fases 3, 4 e 5. As Fases 1 e 2 são as que manipulam os dados brutos das amostras.

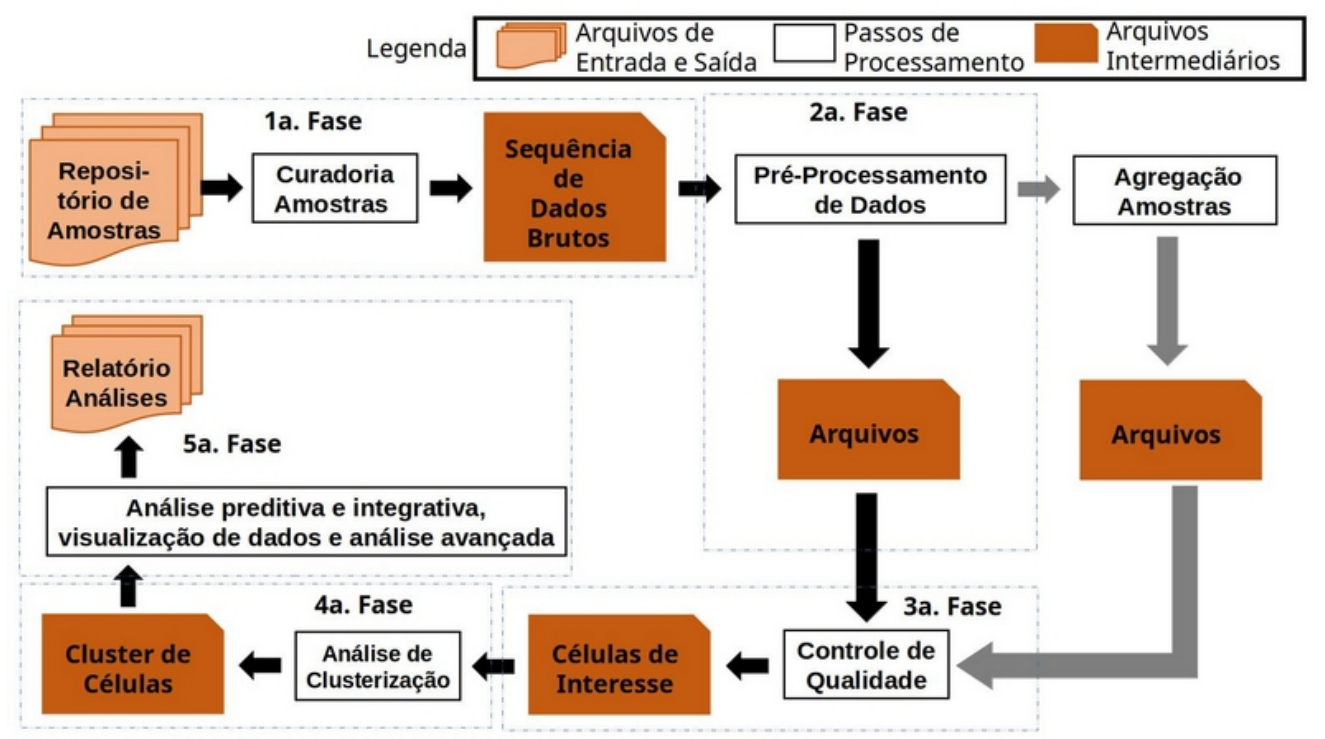

Figura 1. Diagrama conceitual do workflow Cellheap. As caixas pontilhadas representam diferentes fases.

\subsection{Fase 1}

A primeira fase consiste no download dos dados brutos referentes às amostras selecionadas. Para esta fase foram criados dois scripts: um com informação sobre a 
amostra, download e validação, e outro com a geração de arquivos de arquivos divididos e nomeados de acordo com a entrada esperada na Fase 2.

Para obter maior visibilidade no processo, incialmente, o comando $v d b$-dump -info é invocado com a identificação da amostra considerada. O seu resultado é escrito na saída padrão e contém diversas informações como tamanho total da amostra, link de onde ela foi recebida, sua data de entrada no banco de dados entre outras informações. O download é realizado com o comando prefetch do pacote de software sratoolkit do National Center for Biotechnology Information (NCBI). Este pacote é disponibilizado como módulo no computador Santos Dumont e inclui todos os comandos utilizados nesta fase. Para garantir a ausência de falhas no download, o comando vdb-validate é executado em seguida. Como não existe dependência entre diferentes amostras, é possível usar este script de forma paralela usando o paradigma bag-of-tasks.

Obtidos os arquivos sra e validados, é preciso convertê-los para o formato mais apropriado à leitura da ferramenta Cellranger count na Fase 2. Para isto, o segundo script da Fase 1 emprega o comando fasterq-dump. Este comando substitui o comando fastq-dump cuja versão é sequencial. O fasterq-dump é multithreaded e permite realizar a conversão com processamento paralelo. Dessa forma, a ferramenta explora os recursos computacionais do supercomputador de forma mais eficiente. Por fim, os arquivos .fastq são compactados com a ferramenta gzip e renomeados para o formato esperado pelo Cellranger count.

\section{Próximos Passos do Workflow}

Nos procedimentos iniciais, cada invocação do primeiro script da Fase 1 aloca um nó computacional do computador Santos Dumont e realiza o download e validação de uma única amostra. Para melhorar a eficiência na utilização de recursos e melhorar o tempo de obtenção das amostras está sendo avaliada a possibilidade de especificar múltiplos identificações de amostra como argumento à este script e distribuir o download das amostras entre vários nós diferentes. Mesmo com a alta capacidade das interfaces de rede do supercomputador, o download é seguramente a etapa mais longa desta primeira fase, visto que uma única amostra pode representar a transferência de mais de 100GB de dados. Otimizar esta etapa representa um ganho de agilidade significativo na execução do workflow.

\section{Referências}

Silva, Vanessa S. et al. (2021) "CellHeap: a Workflow for Optimizing COVID-19 Single-Cell RNA-seq Data Processing in the Santos Dumont Supercomputer", In: Proceedings of the Brazilian Symposium on Bioinformatcs, Lecture Notes in Bioinformatics serires, Springer, 2021.

Nicolás, Marisa F. e Costa, Maiana O. C. (2021) "Single-cell RNA sequencing (scRNAseq)", Notas de Aula "Seminário Inova Covid19”, Brazil. 